\title{
Extra Oral 3D Scans on the go!
}

\author{
Akanksha Shukla ${ }^{1}$, Gurkeerat Singh ${ }^{2 *}$, Gaurav Saluja ${ }^{3}$ and Anu Rathi ${ }^{4}$ \\ 1,3,4 Postgraduate Resident, Department of orthodontics and Dentofacial Orthopaedics, Sudha Rustagi College of Dental Sciences \& Research, Faridabad, India \\ ${ }^{2}$ Vice principal, Professor \& Head, Department of orthodontics and Dentofacial Othopaedics Sudha Rustagi College of Dental Sciences \& Research, Haryana, \\ India
}

*Corresponding author: Gurkeerat Singh, Vice Principal, Professor and Head, Department of orthodontics and dentofacial orthopaedics, Sudha Rustagi College of Dental Sciences and Research, Faridabad, Haryana, India.

Received Date: November 12, 2020

Published Date: November 30, 2020

\section{Mini Review}

Improvement of facial esthetics has long been the primary goal of any orthodontic therapy. The evidence for this can be traced as far back as 1904, when Victor Hugo Jackson [1] provided us with the three primary aims and objectives of orthodontic treatmentFunctional efficiency, structural balance and Esthetic harmony. As the understanding of soft tissue limitations [2] of orthodontic treatment with respect to function and stability proceeded, the paradigm shift from hard tissue to soft tissue emerged as one of the most iconic events in the history orthodontic diagnosis and treatment planning [3]. Face centered diagnosis, has therefore gained much popularity in recent years. With the advent of recent 3D technology, it has become possible to better visualize the face in all three planes to have deeper understanding of the demands and needs of every patient. The aim of this paper is to introduce a novel method of extra oral 3D scanning that can act as an adjunct to the existing diagnostic records already in place.

\section{3-Dimensional Extra oral Scanning Systems}

There are a range of 3D technologies available to us today for obtaining the extra oral scans. The commonest ones being Cone Beam Computed Tomography (СВCT) and Laser scanning. They are highly efficient in scanning the extra oral structures. However, one cannot overlook certain inherent disadvantages of these modalities. Both these technologies have risk of radiation exposure and technique sensitivity as their major drawbacks [4]. Besides, the setup and maintenance demands of these scanners is too high. Low resolution, dependency on facial pliability, poor landmark identification are some other questionable factors [5].

\section{Structured Light-Based Scanning System}

A structured light-based scanner is a fast processing alternative that captures photorealistic images in a noninvasive manner [6]. It makes use of ambient white light making it biologically safe to use. There are principally two major components of structured light-based scanner: a light projector unit and a digital still camera. The light projector unit projects an organized pattern of grids, dots, or stripes of white light onto the surface of the object. The projected light is captured by a camera. It then uses a sensor to identify how the patterns appear after being distorted by the object under different illumination condition to eventually recover the 3D geometry [7].

\section{D Systems ${ }^{\circledR}$ Sense $^{\mathrm{TM}}$ Scanner}

The Sense $\mathrm{T}^{\mathrm{TM}}$ by 3D systems $\AA$ (Figure 1) is a USB powered, portable, handheld, structured light-based scanner. It is a fast, easy and practical solution for everyday practice. The scanner uses shortrange scanning technology from Intel@. The infrared projector is highly sensitive and uses HD colour cameras to capture the reflected light. The scanner is just about 7 inches in height and 5 inches in width with a depth of 1.3 inches, making it really easy to carry anywhere. With an expansive scan value ranging from 0.2-2 metre and operating distance of up to 1.6 metre, this scanner can easily be used to scan any object with ease. The scanner can be connected to any laptop or tablet with either Windows $8 \AA$ or Windows $10 \AA$ or Mac® OS using the USB 2.0 or 3.0 port. The included software (Figure 2) can then be used to translate the captured image with an aspect ratio of 1:1 in real time on the computer device and save the 
image in STL or OBJ file format ready to be 3D printed if and when required.

The Sense ${ }^{\mathrm{TM}}$ Software helps in manipulation of the scans. These scans are compatible with most other software's such as 3D Builder, 3D Viewer (Figure 3) and MeshLab ${ }^{\text {TM }}$ (Figure 4). These software's help in treatment progress simulations and superimpositions (Figure 5) as well as 3D printing of the models

Figure 1: The handheld portable SenseTM 3D structured light-based scanner.

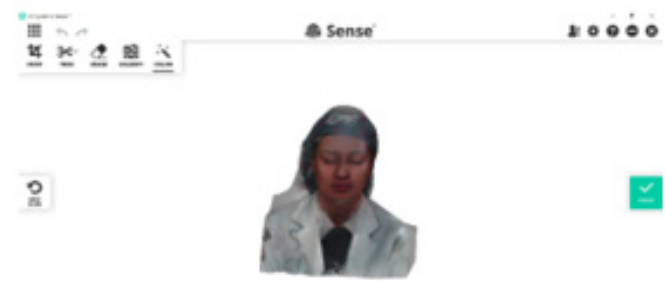

Figure 2: The Sense ${ }^{\mathrm{TM}}$ software interface.

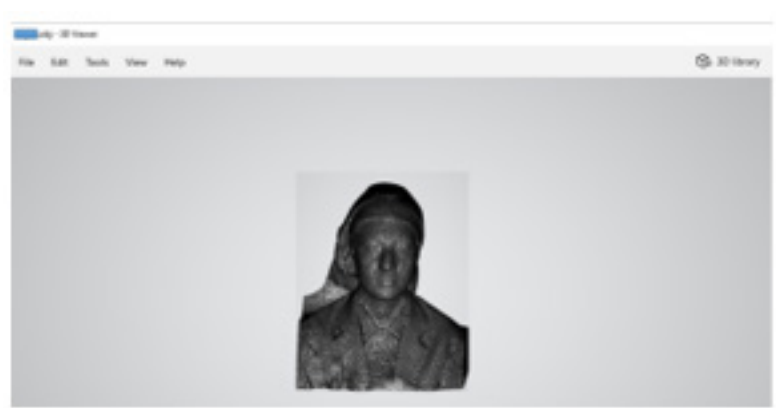

Figure 3: The 3D Viewer ${ }^{\mathrm{TM}}$ software interface.
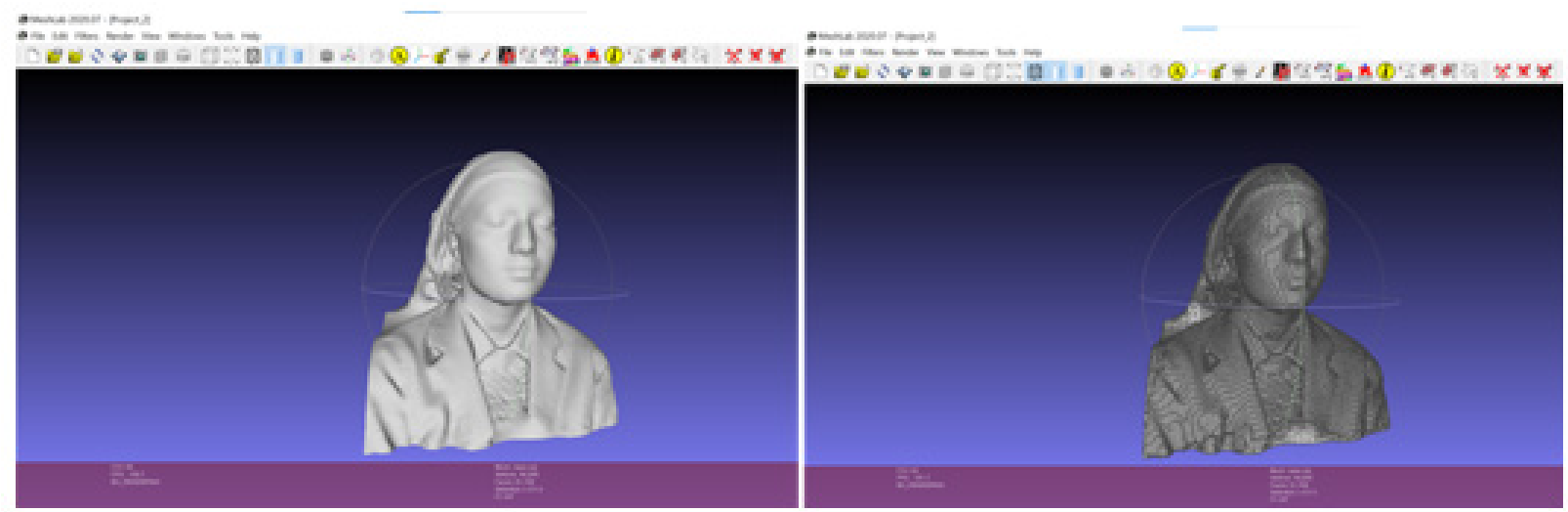

Figure 4: The MeshLab ${ }^{\mathrm{TM}}$ software interface. 


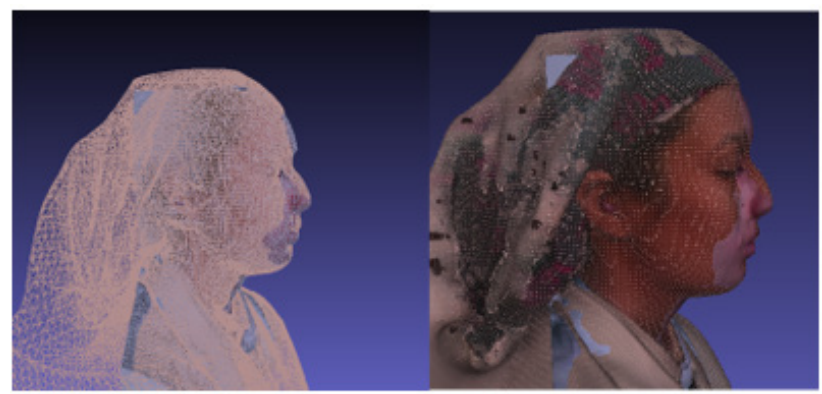

Figure 5: Treatment progress superimpositions.

\section{Scanning Process}

The scanner comes with a tripod thread at the bottom. This means that the scanner can be kept stationary on a tripod and object be rotated to take the scan. A more practical way would be to keep the object stationary and rotate the scanner around it by holding it with your hands and maintaining the scanning distance. The software offers three modalities to capture the scantwo modalities for a person (Head and shoulders and Full Body) and one modality for an object ( 8 inch-10 feet). This ensures the accuracy of geometry as well as maintenance of surface pliability. The only compulsory requirement for the scanning process is a well-lit room so that equal amount of light is reflected and captured by the camera (Figure 6).
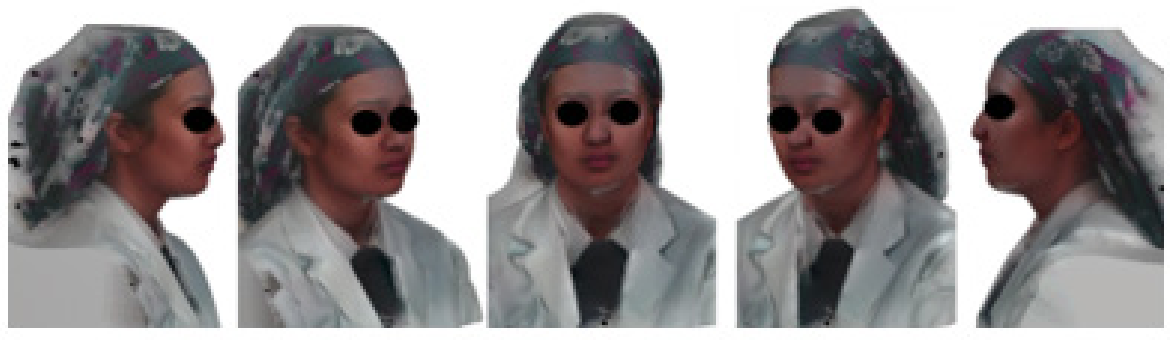

Figure 6: Extra oral scans as achieved by the portable scanner.

\section{Conclusion}

Portable structured light-based scanner provides the advantages of 3D extra oral scanning in the hands of the practitioner without any extra baggage. An easy to use interface and convenience of real time fast scanning can revolutionize the way diagnostic records are taken. It can be used for patient education also. Better visualizations will help in patient motivation and increase their compliance towards certain orthodontic appliances. The idea of going 3D with diagnostic records is fascinating and challenging. This scanner is a step forward in this direction making it more practical, adaptable and economical

\section{Acknowledgement}

None.

\section{Conflict of Interest}

No conflict of interest.

\section{References}

1. Jackson VH (1904) Orthodontia, $1^{\text {st }}$ (edn,). Philadelphia: JP Lippincott, P: $11-21$.

2. Ackerman JL, Proffit WR (1997) Soft tissue limitations in orthodontics: treatment planning guidelines. Angle Orthod 67: 327-336.

3. Ackerman JL, Proffit WR, Sarver DM (1999) The emerging soft tissue paradigm in orthodontic diagnosis and treatment planning. Clin Orthod Res 2(2): 49-52.

4. Miracle AC, Mukherji SK (2009) Cone-beam CT of the head and neck, part 1: physical principles. AJNR Am J Neuroradiol 30(6): 1088-1095.

5. Bush K, Antonyshyn 0 (1996) Three-dimensional facial anthropometry using a laser surface scanner: validation of the technique. Plast Reconstruct Surg 98: 226-235.

6. Webster JG., Bell T, Li B, Zhang S (2016) Structured Light Techniques and Applications. In Wiley Encyclopedia of Electrical and Electronics Engineering, JG Webster (edt,).

7. 3D systems, 3D systems software support user guide. 